\title{
Understanding the Social Vulnerability of Coastal Communities
}

\author{
Regina P. Junio, Aurora C. Gonzales, and Teresita G. Montaño
}

\begin{abstract}
The Philippines ranks as one of the countries most vulnerable to increased severity of tropical storms. Its vulnerability to climate change is amplified by it archipelagic geography and the fact that it is a developing country. This study aims to understand the factors affecting the social vulnerability of fourteen (14) coastal barangays of Zamboanga City to climate-related hazards using participatory and community-based approaches. Results show that coastal communities and coastal resources have been exposed to climate-related hazards like floods, long periods of drought, erratic rainfall patterns, landslide, storm surge, sea-level rise, receding shoreline and warmer seas. Coastal communities' sensitivity to climate-related hazards relies mainly on their dependence on coastal resources for subsistence, livelihood and socio-cultural activities. Factors that affect their level of capacity to adapt include their local environmental knowledge, financial status, ability to plan and re-organize, livelihood diversity, attachment to place and attachment to livelihood.
\end{abstract}

Index Terms - Social vulnerability, vulnerability assessment, climate change.

\section{INTRODUCTION}

Climate Change is "any change in climate over time, whether due to natural variability or as a result of human activity" [1]. Although the climate change impact is geography specific, the most vulnerable are those who come from countries where many already struggle with poverty, inequality, poor health and nutrition, and environmental degradation. They also have the least capacity to cope and adapt to the adverse effects of climate change [2]. Due to its geographical location and physical characteristics, the Philippines is considered one of the most disaster-prone countries in the world [3]. The areas that are most vulnerable to the impacts of climate variability and extremes include tropical forest ecosystems, agricultural ecosystems, coastal and low-lying areas, small islands, inland water ecosystems, wet plains and mangrove areas [4].

This paper looked into one of the dimensions of vulnerability-social vulnerability. Ballesteros [5] defines +social vulnerability as the inability of people, organizations, and societies to withstand adverse impacts from multiple stressors to which they are exposed. Specifically, it looked into the factors affecting coastal barangays' level of sensitivity and adaptive capacity to changes brought about by

Manuscript received September 16, 2014; revised January 5, 2015. This work was supported in part by the Commission on Higher Education through its Higher Education Regional Research Center.

The authors are with Ateneo de Zamboanga University, La Purisima St., Zamboanga City, 7000 Philippines (e-mail: rjunio@gmail.com, gonzalesaurc@adzu.edu.ph, montanoterg@adzu.edu.ph). increased severity and frequency of climate-related hazards.

Social vulnerability was measured as a function of sensitivity and adaptive capacity [6]. Sensitivity was defined as the level of dependency of the coastal communities to coastal resources for food, livelihood and socio-cultural activities [7]. Adaptive capacity was defined as the ability of a system to adjust to climate change (including climate variability and extremes) to moderate potential damages, to take advantage of opportunities, or to cope with the consequences [1]. Adaptive capacity will influence social systems and behavior and is therefore essential to adaptation planning, and a determinant of social vulnerability.

\section{METHOD}

This study made use of descriptive-qualitative design to measure the level of social vulnerability of the selected coastal barangays of Zamboanga City. Community-based participatory approaches based on the Climate Vulnerability and Capacity Analysis (CVCA) framework developed by CARE in 2009 were used to gather and analyze data on community-level social vulnerability [8]. Community-Based Hazard Mapping, Historical Timelining and Seasonal Calendaring were among the community-based workshop conducted to gather primary data and to validate the data gathered from the household survey and key informant interviews.

Household level survey was used to gather data on the coastal barangays' socio-demographic profile and to measure the barangays' level of sensitivity and adaptive capacity towards climate-related changes and hazards. A total of 436 households were surveyed following a multi-step sampling technique where each coastal barangay was sampled following an elevation grid of 300 meters by 100 meters located within 300 meters from the established shoreline to the national highway. Majority of the respondents is indigenous peoples (Tausug at $31.42 \%$ and Sama-Badjao at $19.27 \%$ ) followed by Chabacano (25.92\%), and Bisaya $(11.93 \%)$.

Key informant interviews and field observations were used to validate data gathered from community workshops and the survey.

The study was conducted in selected coastal communities (barangays) of Zamboanga City, Philippines. The barangays were selected using these criteria: risk exposure, poverty index, population density, and accessibility and staff security. Based on these criteria, six (6) barangays (Victoria, Arena Blanco, Bolong, Sangali, Manicahan and Vitali) were selected from the East Coast, three (3) barangays (Talon-Talon, Mariki and Campo Islam) from the city proper, 
and five (5) barangays (Ayala, Talisayan, Sinunuc, Recodo and Labuan) from the west coast.

\section{RESULTS AND DISCUSSION}

\section{A. The Coastal Barangays}

Zamboanga City is located in the southernmost part of the Zamboanga Peninsula, 850 kilometers south of Manila. The southwest and eastern sides of the city are bounded by irregular coastlines with generally rocky terrain with occasional stretches of sandy and gravely beaches. The coastal profile usually descends abruptly towards the sea. It has a total of 98 barangays, and approximately 30 of these are situated along the coastal area and are generally coastal resource dependent for food and livelihood. The impacts of climate change on resources and communities may intensify the already volatile peace and security situation of the city. Zamboanga's coastal zone provides a diverse range of natural resources and favorable conditions for social and economic development. However, its coastal ecosystems are fast becoming highly vulnerable, due to several natural coastal hazards, over-exploitation, and other human activities. These hazards are being intensified by climate change and associated rising sea levels.

The Zamboanga Peninsula Medium-Term Regional Development Plan (2011) cited that most of the frequent disaster occurrences in the Zamboanga Peninsula region from 1999 to 2009 are hydrologic hazards, particularly flooding, storm surge, and flash floods. The region also ranked second in terms of the largest land area most susceptible to a one-meter rise in sea level.

Based on Zamboanga City's Comprehensive Land Use Plan, six (6) barangays (Victoria, Arena Blanco, Bolong, Sangali, Manicahan and Vitali) from the East Coast fall under the agro-mariculture zone, while three (3) barangays (Talon-Talon, Mariki and Campo Islam) from the city proper are considered urban residential zone. Five (5) barangays (Ayala, Talisayan, Sinunuc, Recodo and Labuan) from the west coast are considered industrial economic zone. The barangays under the agro-mariculture zone are considered as the City's food basket as they are the main producers of rice, vegetable and farmed marine products such as crabs, prawns, milkfish, seaweed. The three barangays under the urban residential zone are three of the most populated barangays within the City's seven-kilometer radius. They are all located along the coastal areas where a majority of the population is dependent on coastal resources for livelihood. The City's industrial economic zone is also located along the coastal area. This is where bulk of canning industry (e.g. sardines, tuna, other marine products) is found.

\section{B. Exposure to Climate-Related Hazards}

Using community-based hazards mapping and historical timelining, the communities were able to understand their level of exposure or the extent to which their infrastructure, resources, and the community experiences changes in climate. Results of the community-based workshops show that the all the coastal barangays covered by the study have already been exposed to climate events and patterns that affect their communities, including other changes linked with changes induced by climate effects. Among the climate-related hazards they have experienced over the years are floods, landslides, long periods of drought, proliferation of pests and crop diseases, storm surge, sea-level rise and warner seas. The agri-mariculture zone, including Manicahan and Vitali, have experienced repeated flooding that affects social infrasructure and livelihood. Ayala, Labuan, Manicahan and Vitali, all of which have extensive agriculture as main source of livelihood have reported having experienced long periods of drought. Landslides affect the upland communities of Sinunuc, Victoria, Vitali and Ayala. Coastal areas of Ayala, Bolong, Campo Islam, Labuan, Mariki, Recodo, Sinunuc, Talisayan, Talon-talon and Victoria have been exposed to storm surges that destroy social infrastructure, disrupt normal community activities and damage livelihood. Barangays Bolong, Labuan and Recodo have observed receeding shoreline, sea-level rise and warmer seas in the last 20 years.

\section{Sensitivity}

The potential impact of the exposure of the community or its ecosystem to which it is dependent on will be determined in part by its sensitivity. Vulnerability to climate change increases as sensitivity increases. Results show that coastal barangays manifest dependency on coastal resources for subsistence, livelihood and socio-cultural practices.

Of the 14 barangays studied, two (2) (Manicahan and Sangali) manifested high dependency on coastal resources for their primary and secondary sources of income. Even surrounding industries in the area are also dependent on coastal resources either as source of primary or secondary raw materials. Six (6) barangays (Talon-Talon, Mariki, Arena Blanco, Sinunuc, Ayala, and Labuan) showed medium dependence on coastal resources for primary and secondary source of livelihood while the remaining six (6) (Vitali, Bolong, Victoria, Recodo, and Talisayan) barangays showed low dependence on coastal resources as primary source of livelihood showed low dependency on coastal resources for main source of livelihood.

The barangays' dependence on coastal resources and coastal resource services prove them sensitive to the impacts of climate-related hazards affecting coastal resources. Marshall explains that the sensitivity of individuals who rely on ecosystem goods and services is largely determined by how strongly they depend on the specific goods and services that will be affected by environmental change [9].

Results show that communities who show high sensitivity also show high degree of livelihood specialization (i.e. fishing, fishing-related economic activities and seaweed farming). The communities' main source of income, secondary sources of income and even the breadth and availability of other local industries are coastal resource dependent. Machilis and Force [10] presented that specialists, having narrower skills, are likely to be more sensitive to climate-induced changes in resources. As compared to generalists, those that have a greater skill set due to a variety of income source and or broader variety of industries may be more adaptable and therefore less sensitive to climate-induced changes in the resource [11]. This means that specialists, as a whole can be potentially highly sensitive to 
coastal environmental changes because the economic base of a community is heavily reliant on coastal resources. As sensitivity decreases, the community's social vulnerability also decreases.

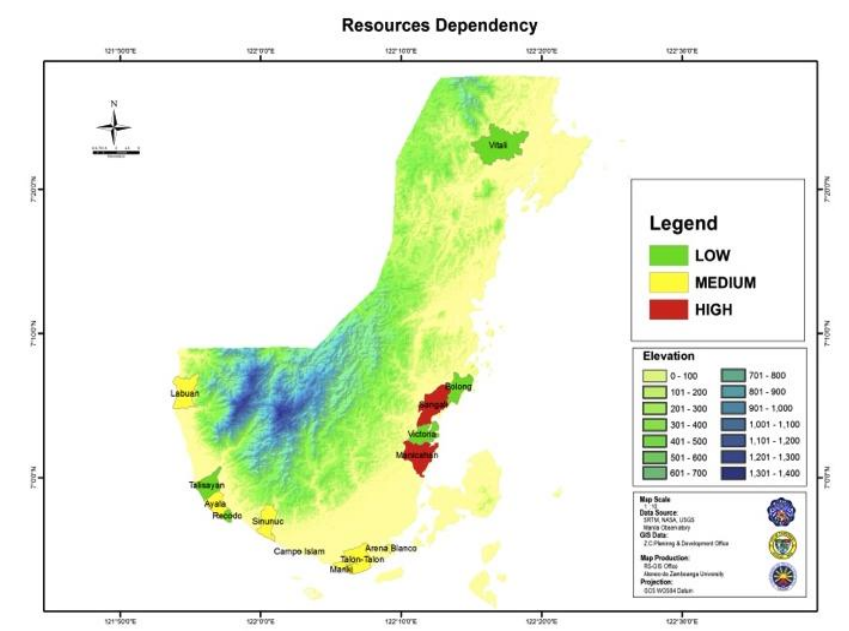

Fig. 1. Level of dependence of selected communities on coastal resources.

Other than high dependence on coastal resources for livelihood, Barangays Manicahan and Sangali also manifested high dependence on coastal resources for subsistence or food. The coastal communities of Manicahan and Sangali are subsistent fisherfolks. This means that most families who live by the coastal area are highly dependent on coastal resources for everyday food. Other communities dependent on coastal resources for food include Ayala, Arena Blanco, Labuan, Mariki, Sinunuc, Talisayan, Talon-Talon, and Vitali. Only Barangays Bolong, Victoria, and Recodo, on the other hand, showed low dependency on coastal resources for food.

As more than $50 \%$ of the household surveyed belong to indigenous peoples groups, Barangay Talisayan exhibited high dependence on coastal resources for their socio-cultural and traditional practices while eleven other barangays showed medium dependence. Only Vitali, Sangali and Victoria showed low dependence on coastal resources for the of practice socio-cultural and traditional activities as this three barangays are mostly inhabited by households who do not belong to any indigenous peoples group.

\section{Adaptive Capacity}

Adaptive Capacity is also a component of vulnerability as adaptive capacity determines which of the potential impacts of a climate-related hazard will actually happen. Adaptive capacity will influence social systems and behavior and is therefore essential to adaptation planning, and is a determinant of social vulnerability.

Among the factors that positively affect adaptive capacity, the study showed that most households have high level of interest in adapting to change. Interest in adapting to change is a dimension of adaptive capacity that explains the degree to which communities are capable of "self-organization". Individuals or communities with high interest in adapting to change have either higher financial, social and/or emotional flexibility to do so. In the case of the coastal communities of Zamboanga, most communities highlighted their social and emotional flexibility. They pride themselves in their ability to provide support to each other as shown by their close family ties and strong social network.

Family characteristic is another strength common to most coastal communities. Although most households have school-aged children, they are still able to move easily in times of calamity as social and family networks are able to provide support. This is especially true for the coastal communities of Vitali, Victoria, Sinunuc, Manicahan and Talisayan.

Among the factors that decrease households' ability to adapt to climate-induced changes are their lack of livelihood diversity and their attachment to livelihood. Coastal communities that showed high social vulnerability were highly dependent on fishing and seaweed farming as their main source of livelihood. Sangali, Arena Blanco, Talon-Talon, Mariki, Campo Islam and Labuan showed this characteristic. These communities also strongly identify themselves as fisherfolks and seaweed farmers, and are highly attached to these livelihoods. This attachment to occupation means that when they are no longer able to continue their means of earning, they do not only lose their income but also their identity [12]. This is validated by the results on sensitivity showing eleven barangays exhibiting high and medium dependence on coastal resources for their socio-cultural and traditional practices. This means that the community, as a whole can be potentially highly sensitive to coastal environmental changes because the economic base of a community, their food source and their socio-cultural practices are reliant on coastal resources. Most coastal communities also show high attachment to place. This means they prefer to have the stability and familiarity of staying in the same community despite the glaring risks facing them. This preference often leads to lower capacity to adapt and effectively respond to climate change [13].

The coastal barangays' lack of transferable skills, low level of education, the lack of opportunity and openness for other types of employment and openness to relocate lower their capacity to adapt to change. Communities that derive income from multiple sources or resource types or are more able to switch between occupations or seek opportunities elsewhere tend to have higher adaptive capacity. This is true only for coastal barangays of Recodo, Sinunuc, Talisayan, Vitali, Victoria and Sangali. The other barangays exhibited low to very low level of education and employability.

The coastal barangays are generally weak in their perception of risk. The community or individual's ability to cope and adapt is associated with how they perceive risk associated with change [14]. In the case of most of Zambonga City's coastal barangays, the barangays' response to change has been the same all through the years. During disasters, the communities seek and wait for help from their local governments. Very little is done on the individual or household level to prevent exposure to climate-related hazards. There is very limited change in beliefs, attitudes, judgment and even practices in the community even after repeated exposure to hazards.

The coastal barangays have mostly exhibited high local environmental knowledge. They have invested much time to understand the conditions occurring around the community and may have developed high adaptability towards those 
conditions. Their familiarity and adaptability with their surrounding may be linked to their complacency and may lead their decision not move from where they are. Coupled with lack of access to technology, climate information and skills, communities will tend to rely on local environmental knowledge and are unlikely able to prepare and plan effectively for the future [15].

\section{CONCLUSION}

Zamboanga City coastal communities are already exposed climate-related hazards that become more intense and more frequent in the last 20 years. Communities with high sensitivity and low capacity to adapt tend to have high social vulnerability and less able to cope with these climate-related changes. Those with low sensitivity and/or dependency to climate dependent resources and with high adaptive capacity will most likely have low social vulnerability. With low social vulnerability, the probability of the potential impacts of climate-induced changes to happen will be low.

Among the barangays studied, the coastal communities located in Barangays Ayala, Arena Blanco, Talon-Talon, and Mariki have high social vulnerability. This means that these communities might not be able to adapt to the changes brought about by the changing climate, and the potential impacts of these changes will most likely eventuate. Livelihood, social infrastructure, health, and over-all social well-being might be adversely affected. The residents' attachment to livelihood, lack of transferable skills, lack of livelihood diversity, and level of poverty will decrease their ability to adapt to change and thus increase vulnerability.

\section{ACKNOWLEDGMENT}

This study was conducted by the Ateneo Research Center of the Ateneo de Zamboanga University with support from the Commission on Higher Education.

\section{REFERENCES}

[1] IPCC, "Climate change 2007: Impacts, adaptation and vulnerability," in Fourth Assessment Report, M. L. Parry, O. F. Canziani, J. P. Palutikof, P. J. van der Linden, and C. E. Hanson, Eds. Cambridge University Press, Cambridge, UK, 2007.

[2] A. Hammill, T. M. Tanner, C. Robledo et al., "Portfolio screening to support the mainstreaming of adaptation to climate change into development assistance," Climatic Change, vol. 84, no. 1, pp. 23-44, 2007.

[3] J. Fortes, "Report on survey results," presented at Workshop on Financial Strategies Managing Economic Impact of Natural Disaster at the Macro-Meso-, Micro-Level, Manila, Philippines, May 22-24, 2006.

[4] Gozun. (2011). Climate change officials urges relocation of coastal settler. Climate Change Philippines. [Online]. Available: http://climatechangephilippines.blogspot.co.uk/2011_06_01_archive. html

[5] E. Ballesteros, Plan de Acción Para la Conservación del Coralígeno y de Las Demás Bioconcreciones Calcáreas del Mediterráneo, Regional Activity Centre for Specially Protected Areas (RAC/SPA), Tunis, 2008.
[6] Nelson et al., "Using adaptive governance to rethink the way science supports Australian drought policy," Environmental Science and Policy, vol. 11, pp. 588-601, 2008.

[7] N. A. Marshall et al., A Framework for Social Adaptation to Climate Change: Sustaining Tropical Coastal Communities and Industries, International Union for the Conservation of Nature (IUCN), 2009.

[8] CARE, Climate Vulnerability and Capacity Analysis Handbook, $1^{\text {st }}$ ed. 2009.

[9] N. A. Marshall, Understanding Social Resilience to Climate Variability in Primary Enterprises and Industries, Global Environmental Change, 2009.

[10] G. E. Machilis and J. E. Force, "Community stability and timber-dependent communities," Rural Sociology, vol. 53, pp. 220-234, 1988.

[11] J. J. Poggie and C. Gersuny, "Fishermen of Galilee," Rhode Island Univeristy Marine Bulletin Series Number 17, The Human Ecology of a New England Coastal Community, National Oceanic and Atmospheric Administration Kingston, 1974.

[12] M. Minnegal, T. F. King, R. Just, and P. D. Dwyer, "Deep identity, shallow time L sustaining future in victorian fishing communities," The Austalian Journal of Anthropology, vol. 14, pp. 53-71, 2004.

[13] R. C. Stedman, "Sense of place as an indicator of community sustainability," The Forestry Chronicle, vol. 75, pp. 765-770, 1999.

[14] J. W. Richie et al., "Risk management strategies using seasonal climate forecasting in irrigated cotton production: A tale of stochastic dominance," Australian Journal of Agriculture and Resource Economics, vol. 48, pp. 65-93, 2004.

[15] N. A. Marshall, "Can policy perception influence social resilience to policy change?” Fisheries Research, vol. 86, pp. 216-227, 2007.

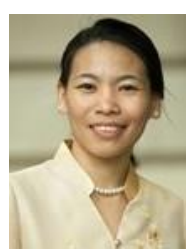

Regina P. Junio has served as a research associate and an assistant professor at the Ateneo de Zamboanga University for 16 years. She also served as a climate change advisor for Voluntary Service Overseas-Malawi Programme Office during her being as an international volunteer. She graduated from the Ateneo de Manila University with a master degree of science in chemistry education and did post-graduate studies on environmenta policy and climate change as a Hubert H. Humphrey fellow at Cornell University in Ithaca, New York.

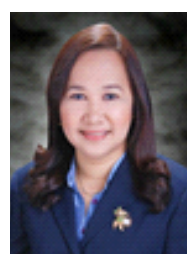

Aurora C. Gonzales is now the director of the Ateneo Center for Leadership and Governance (ACLG) of the Ateneo de Zamboanga University, Philippines. She is an A.B. psychology graduate from the Western Mindanao State University in Zamboanga City in 1990. She obtained her master of arts degree in theology, Majoring in pastoral ministry, from the Ateneo de Davao University in 1998. Her research interests include peace initiatives and university programs on social involvement and community extension services.

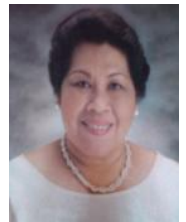

Teresita G. Montaño has served as a chemistry professor at the Ateneo de Zamboanga University for 38 years. She also served in several administrative positions in the same university, the highest of which is as the senior dean of the colleges. She got the bachelor degree of science in chemistry, M.S. degree in chemistry education from the Ateneo de Manila University and her Ph.D. degree in environmental science with cognate in organizational development and management from the University of the Philippines in Los Baños. At present she is the director of the Ateneo Research Center, Ateneo de Zamboanga University. 